\title{
UMA HISTÓRIA TODA SUA: TRAJETÓRIAS DE HISTORIADORAS BRASILEIRAS, 1940 - 1990
}

\section{A History all your: trajectories of women brazilian historians, $1940-1999$}

\section{Carmem Silvia da Fonseca Kummer Liblik ${ }^{11}$}

\section{Resumo}

Mapear, investigar e analisar as trajetórias intelectuais e profissionais, bem como explorar a riqueza das narrativas biográficas que expressam as experiências pessoais, interpessoais e de vida das historiadoras brasileiras, constituem a natureza essencial da problemática deste artigo. Para tanto, delimitaremos duas gerações de historiadoras profissionais que se sobrepõem, as quais estiveram vinculadas às universidades públicas brasileiras conforme suas produções acadêmicas e prática docente: $1^{\text {a }}$ geração (19401970), responsável pela iniciação dos estudos historiográficos, escolha de objetos e procedimentos vinculados à História científica, ao lado da consolidação das cátedras; e $2^{\mathrm{a}}$ geração (1971-1990), responsável pelo início dos primeiros cursos de pós-graduação no país, os quais voltaram-se para novos temas, propostas metodológicas, extinção evolutiva das cátedras e, sobretudo, para pesquisas regularmente organizadas. Tal problemática será analisada mediante o questionamento se o gênero se constitui, ou não, como elemento estruturante na diferenciação e profissionalização dos(as) historiadores(as) no campo disciplinar histórico. Espera-se, com isso, compreender inicialmente os papéis assumidos e a maneira como as historiadoras brasileiras se inseriram no âmbito universitário e contribuíram para a consolidação das pesquisas historiográficas, constituindo assim, suas trajetórias intelectuais e profissionais.

Palavras-chave: historiadoras brasileiras, gênero, trajetória intelectual e profissional

11 Doutoranda em História. Programa de Pós-Graduação em História - Universidade Federal do Paraná. e-mail: carmemsfk@gmail.com 


\section{Abstract}

Map, investigate and analyze the intellectual and professional trajectories, as well as exploring the wealth of biographical narratives that express personal, interpersonal and life experiences of Brazilian historians, constitute the essential nature of this paper. Therefore, we will delimitate two generations of professional historians (which overlapping), linked to the Brazilian public universities, according to their academic works and teaching practice: the 1st generation (1940-1970), responsible for the initiation of historiographical studies, choice of objects and procedures related to scientific History, alongside the consolidation of the university chairs, and 2nd generation (1971-1990), responsible for the initiation of the first postgraduate courses in the country, which have turned to new subjects, methodological proposals, progressive extinction of the university chairs and, mainly, for regularly organized research. This issue will be examined by questioning whether gender constitutes, or not, a structuring element in the differentiation and professionalization of the historians in the disciplinary field of history. It is expected, therefore, understand the roles assumed initially and how the women Brazilian historians were inserted in the university and contributed to the consolidation of historiographical research, thus as well, their intellectual and professional trajectories.

Keywords: Brazilian historians, gender, intellectual and professional trajectories

Partimos do pressuposto de que na constituição da epistéme ocidental o sujeito conhecido é quase sempre masculino. A partir disso, quando imaginamos um grande historiador, instintivamente o imaginamos homem, tanto é que com certa frequência ouvimos a expressão "o pai da história" sendo raríssimo pensarmos na possibilidade eventual de que a ciência histórica tem uma "mãe". Apesar disso, o interesse e a investigação pela vida, envolvimento, escrita e atuação das mulheres que escreveram narrativas históricas sobre o passado - quer seja sob o ponto de vista amador e desvinculado da academia, quer seja sob a perspectiva da história considerada científica - e que se profissionalizaram na carreira como professoras e pesquisadoras, têm sido manifestados nos debates historiográficos internacionais desde o início da década de 1980 e se aprofundado especialmente nos primeiros anos do século XXI.

Sobre este tema, a pesquisa que merece grande destaque, devido em 
grande parte à sua erudição e contribuição ao campo epistemológico e historiográfico e, sobretudo, à menção sobre a construção da prática profissional do historiador, é Gender of History. Man, Women and Historical Practice (1998), realizada pela historiadora americana Bonnie G. Smith e traduzida no Brasil em 2003, como Gênero e História: Homens, Mulheres e Práticas Históricas. A autora se propõe a retomar e oferecer uma nova perspectiva de abordagem acerca de uma preocupação antiga, ou seja, de uma problemática original levantada pela primeira vez na década de 1980 por Natalie Zemon Davis no artigo Gender and Genre: Women as Historical Writers, 1400-1820, cuja linha principal de argumentação consiste na necessidade de tornar visível o interesse das mulheres pela história e pela escrita histórica.

Em seu livro, Smith delimita e analisa um terreno ainda pouco explorado, qual seja, a história do relacionamento das mulheres profissionais e amadoras com a narrativa histórica, bem como os valores e representações de gênero da ciência histórica. Conforme a autora, a história dos últimos dois séculos não foi escrita apenas pelos homens e tampouco diz respeito exclusivamente aos homens. Nesse sentido, seria necessário questionar porque a tradição historiográfica situa apenas escritores canônicos do sexo masculino no centro da história, sendo também importante mostrar o interesse e o relacionamento das mulheres com esta ciência. Assim sendo, desde o final do século XVIII, as mulheres consideradas então como amadoras, demonstraram um crescente interesse sobre as questões do passado e desde o final do século XIX algumas inglesas e americanas já começaram a trilhar carreiras satisfatórias no ensino superior. Mesmo assim, é importante assinalar que muitas historiadoras continuavam a ser chamadas de amadoras até início do século $X X$, uma vez que não tiveram o reconhecimento das associações institucionais e dos profissionais do sexo masculino. ${ }^{12}$

12 A falta de reconhecimento às amadoras relaciona-se exclusivamente com o desenvolvimento do profissionalismo no século XIX. Nesse período, o foco do historiador foi direcionado para treinamentos, seminários, interação somente com documentos autênticos, imparcialidade, ou seja, o homem historiador constituiu-se e era visto como um especialista experiente que analisava com imparcialidade e sobriedade os fatos históricos. Cientistas históricos estabeleciam polaridades entre profissionalismo e amadorismo, entre história política e ninharias culturais. Foi com o diálogo da visão amadora mais popular - isto é, com a feminilidade, com a vida cotidiana e sua respectiva "superficialidade" - que a ciência histórica tomou forma oposta como uma questão de importância nacional, como verdade uni- 
Sobre os elementos que configuram a inserção da historiadora na vida profissional, tema que nos interessa, Smith indaga sobre as primeiras muIheres profissionais que receberam instrução universitária na Inglaterra e EUA a partir de 1870. Teriam elas um desempenho profissional tal como os homens tiveram? Conseguiram elas despersonificar-se do papel de mães e esposas, apesar de que a persona coletiva das mulheres vitorianas e americanas era o próprio "sexo"? Conseguiram elas, e de que maneira, se afastar do amadorismo? Apesar de não ser possível inseri-las dentro de uma categoria de identidade profissional e tampouco de feminilidade, as mulheres historiadoras tornaram-se profissionais no século XX somente quando ingressaram nas universidades e, paralelo a isso, quando iniciaram uma tentativa pela busca de definição e indistinção de gênero em suas pesquisas, sob o ponto de vista do auxílio das práticas narrativas, sociais e profissionais predominantes no meio científico.

Da História para a Literatura, abriremos um parêntese para mencionar uma reflexão que nos é inspiradora e foi enunciada pela escritora Virgínia Woolf que, no ensaio Um teto todo seu, discute as possíveis causas da omissão de escritoras no cânone literário. A autora lança a hipótese de que esta omissão e a dificuldade das mulheres em produzir a escrita literária seriam resultados da falta de condições materiais que garantissem um mínimo de bem estar, autonomia e privacidade para as mulheres. Ao longo de suas reflexões, Woolf afirma que a maior de todas as conquistas feministas seria a liberdade de pensar, classificar, selecionar, emitir opinião e ter autonomia. Assim, a mulher só adquiriria a independência necessária a partir do momento que conquistasse a autonomia financeira e possuísse um teto todo seu, ou seja, um espaço privativo e autônomo para sua escrita. Nessa mesma direção, pensamos que "uma história toda sua" assinala a intenção de problematizar a relação e o envolvimento das mulheres historiadoras brasileiras com a História, com a escrita histórica e com a profissionalização nas universidades. Mas como?

A partir destas reflexões, portanto, podemos assinalar que uma das questões que podem ser delimitadoras para o estudo da trajetória da profissionalização do(a) historiador(a) brasileiro e do processo da institucionalização da História nas universidades brasileiras seria compreender como se deu a participação e atuação de mulheres e professoras historiadoras

versal sem gênero e, ao mesmo tempo, como uma disciplina voltada para homens. In: SMITH, Bonnie.

Gênero e História. Homens, mulheres e a prática histórica. Edusc: Santa Catarina, 2003. 
neste campo intelectual marcado predominantemente pelo androcentrismo, bem como realizar o mapeamento da inserção e da constituição da trajetória profissional e de vida delas nas principais universidades púbicas brasileiras, entre 1940 a 1990. Nessa direção, entende-se que os estudos e a produção acadêmica acerca da profissionalização da mulher historiadora que se insere no corpo docente das universidades brasileiras, tema relativamente ausente na historiografia brasileira ${ }^{13}$, partem de dois eventos importantes relacionados ao desenvolvimento da História, quais sejam: a institucionalização da História científica, conhecimento este restrito às universidades brasileiras e, ao lado disso, a entrada expressiva das mulheres nas universidades a partir da década de 1930 como alunas e, alguns anos depois, como professoras assistentes, adjuntas e depois como catedráticas.

Tendo em vista estas duas considerações e perspectivas históricas, cabe-nos situar primeiramente o ingresso das mulheres nas universidades. Em 1879 a Lei Saraiva permitiu pela primeira vez que as mulheres brasileiras tivessem acesso aos cursos superiores (BLAY, 1991). Contudo, no final do século XIX e início do XX poucas puderam ingressar nos cursos superiores existentes, posto que as Escolas Normais, onde elas faziam seus estudos de nível secundário, tinham o objetivo exclusivo de prepará-las somente para a docência no ensino primário. Paralelo a isso, a visão cultural, social e familiar de que a mulher poderia almejar para si a formação superior era mal interpretada e julgada como inútil e até mesmo como prejudicial para elas ou para a família. Assim, pode-se afirmar que apenas aquelas que receberam o apoio da família e que estudaram em escolas particulares - ou que tiveram professores particulares - estariam melhor preparadas para o exame de ingresso nas universidades (PEROSA, 2010).

Assim sendo, a possibilidade de acesso mais expressivo das mulheres nas universidades se deu efetivamente a partir da década de 1930. Foi um período importante, no qual foi instituído o Decreto $N^{0} 19.851$, de 11 de abril de 1931 - proposto pelo Ministro Francisco Campos - cujo objetivo ele-

13 Os artigos, livros e demais pesquisas vinculadas ao tema proposto limitam-se à escrita memorialística individual de algumas historiadoras, as quais traçam apenas uma trajetória de vida e profissional sem problematizações mais expressivas, a saber: BLAY, Eva; LANG, B. S. G. Mulheres na USP: Horizontes que se abrem. 1'a . ed. São Paulo: Humanitas, 2004. LOBO, Yolanda e FARIA, Lia. Vozes femininas do Império e da República. Rio de Janeiro: FAPERJ, 2008. 
mentar dizia respeito à reforma do ensino superior, constituindo assim um dos motivos a suscitar o surgimento das Faculdades de Filosofia, Ciências e Letras (FFCL) no país, uma vez que a anterior formação de profissionais em nível superior no Brasil estava limitada às áreas de Medicina, Direito e Engenharia ${ }^{14}$. A partir desta data e nas décadas posteriores, ingressar na Universidade de São Paulo, na Universidade do Rio de Janeiro, na Universidade do Paraná, na Universidade do Rio Grande do Sul, dentre outras universidades públicas, portanto, significava inserir-se num espaço público, misto, fora do restrito controle moral imposto pela religião e pelas famílias, no qual as mulheres estariam expostas à influência de um ambiente intelectual laico e à convivência com jovens de origens sociais e culturais múltiplas (PEROSA, 2010).

Primeiramente, a aquisição dos diplomas superiores deu-se predominantemente nos cursos voltados para receber a clientela feminina, tais como Letras, Pedagogia, Psicologia, História, Serviço Social e Belas-artes. Conforme o estabelecimento do Decreto $N^{\circ} 19.851$, tais cursos possuíam em comum o fato de formar professores qualificados para o ensino primário e secundário, e nos anos seguintes também fornecer profissionais para o ensino superior. Conforme a historiadora Alice Canabrava:

Muitas mulheres que frequentaram a USP, quando de sua criação em 1934, puderam fazê-lo através do comissionamento. As mulheres foram as que mais entraram para a Faculdade por este mecanismo, pois elas constituíam a maioria das professoras primárias. Eram mulheres que trabalhavam, não tinham posse, de modo geral dependiam de seus salários. Para poder frequentar uma faculdade não podiam abrir mão do salário. Assim, foi por um ato governamental que estas professoras, mulheres na maioria, moradoras no interior do Estado de São Paulo, puderam vir estudar na capital (CANABRAVA, 2003, p. 7).

No caso da História, se até o início da década de 40 foram poucas as mulheres que frequentaram as faculdades então existentes, pretendemos primeiramente tecer a construção sobre o percurso acadêmico, profissional

14 Trata-se de uma reforma que buscava organizar o Ensino Superior dentro de uma noção de autonomia relativa das instituições de ensino. Suas diretrizes previam que todas as instituições de Ensino Superior, para se constituírem como Universidade, necessitavam estar compostas por no mínimo três das quatro faculdades: Faculdade de Medicina, Faculdade de Direito, Faculdade de Engenharia e Faculdade de Filosofia, Ciências e Letras. É a partir deste decreto que surgem as primeiras Faculdades de Filosofia, Ciências e Letras, nas quais aparecem os primeiros cursos de História e Geografia. 
e de vida das primeiras historiadoras brasileiras, tais como Maria Bárbara Levy, Emília Viotti da Costa, Alice Pfifer Canabrava, Olga Pantaleão, Déa Fenelon, Maria Cecília Westphalen, Helga Piccolo, Maria Yedda Leite Linhares, Mafalda Zemella, Eulália Lobo, Myriam Ellis, Aydil Pires, entre outras, que ingressaram nos cursos de História e realizaram suas atividades como docentes entre 1940 a 1970, fato que por si só as distinguem da média das mulheres de sua geração. Em outras palavras, o simples fato de prosseguirem os estudos após o ensino secundário já nos demonstra o horizonte mais amplo do que o considerado normal para as mulheres à época.

Certamente o ambiente familiar propício e as condições socioculturais devem ser analisados, tendo em vista que uma trajetória profissional de nível universitário não era comum à maioria das mulheres, como demonstra o depoimento da historiadora Eulália Maria Lobo:

A história surgiu muito cedo, porque meu pai tinha muita preocupação de que eu não fosse para uma escola convencional. Ele achava que o ensino era muito rotineiro, baseado na memorização de informação, não despertando espírito criativo. Então, ele teve a preocupação de promover em casa um ensino diferente (LOBO, 2003, p. 240).

Uma vez que o estudo e o mapeamento da atuação e atividades desenvolvidas pelas historiadoras brasileiras inserem-se no contexto particular da entrada das mulheres nas universidades, o segundo aspecto histórico importante refere-se ao próprio processo de institucionalização da História como ciência, no qual elas participaram desde o início no âmbito universitário tendo em vista a criação dos cursos de História. Se até 1930, os estudos históricos ainda estavam fortemente identificados ao projeto do Instituto Histórico e Geográfico Brasileiro, criado em 1838, e a seus congêneres estaduais (GOMES, 2009), o processo de institucionalização do ensino universitário de História nas Faculdades de Filosofia, Ciências e Letras das universidades públicas iniciou-se num período de mudanças quanto aos procedimentos dos estudos históricos, justamente quando se renovavam metodologias de pesquisa, elaboração de perguntas e respostas e análises de fontes e objetos. ${ }^{15}$

15 Novos autores são revelados por meio de obras que propõem "novas interpretações" da história da sociedade brasileira. Oliveira Viana, Gilberto Freire, Sergio Buarque de Holanda e Caio Prado Junior produziram estudos que se tornaram clássicos na definição de outros caminhos para a compreensão 
Ladeando essas transformações relacionadas aos debates dos historiadores a respeito de sua disciplina, do ofício e da escrita da história, começaram a se consolidar também as primeiras revistas acadêmicas de História. Não só isso, mas também se inauguravam os primeiros congressos e sociedades acadêmicas e, com isso, formavam-se novos espaços de sociabilidade para os debates entre historiadores e cientistas sociais brasileiros, nos quais as mulheres passaram a contribuir e atuar profissionalmente.

Sobre este momento de transição e das práticas que institucionalizaram a História, vale citar o depoimento de Emília Viotti da Costa, que ingressou no curso de Geografia e História em 1948 na USP: “...o curso era voltado para a formação geral do professor. A pesquisa em fontes primárias não recebia muito estímulo ou orientação. A maioria dos ensaios que escrevíamos eram somente historiográficos" (COSTA, 2002, p.70). Esta professora prossegue dizendo que "em matéria de pesquisa, recebi pouca orientação. Só fui realmente aprender a pesquisar depois de formada, quando uma bolsa de estudos do governo francês me permitiu estudar em Paris" (COSTA, 2002, p.70). Revela, por fim, que como aluna "fui mais influenciada pelos livros que li e por professores de outros departamentos do que pelos do Departamento de História. Os livros, as personalidades e a assistência de Antonio Candido e Florestan Fernandes foram muito importantes para a minha formação" (COSTA, 2002, p.71).

Observando retrospectivamente esse movimento de transição, verifica-se que naquele período não houve margem para uma "iniciação" à pesquisa histórica propriamente dita, mas sim para o interesse pelas primeiras tentativas de profissionalizar a História, ou seja, por meio de seminários e trabalhos práticos e teóricos, de se formar, senão um ofício de historiador a partir de um curso de graduação, pelo menos a iniciativa de se produzir os primeiros profissionais na área. Essa iniciativa, evidentemente, não abarcava a vida acadêmica de todos os alunos, mas apenas aqueles que conseguiam provar aos mestres a sua disposição e vocação para o culto à pesquisa erudita, sendo naquele contexto social específico, privilegiada a vocação dos homens.

A partir destes dois contextos históricos específicos, isto é, a entrada das mulheres nas universidades, particularmente nos cursos de História, e o processo de institucionalização da pesquisa histórica, a qual contou com

da sociedade brasileira. 
reformulações da prática e procedimentos do historiador, pretendemos realizar o mapeamento e analisar a vida, a prática docente e de pesquisadoras, as práticas profissionais, as relações entre pares e a contribuição das mulheres historiadoras na historiografia brasileira e no desenvolvimento dos departamentos dos cursos de História. Para tanto, iremos delimitar o período de 1940 a 1990, considerando o período inicial da entrada dessas mulheres nos cursos de História e, por extensão, a própria periodização acerca de duas gerações de historiadores(as) profissionais: $1^{a}$ geração (1940-1970), responsável pela iniciação e consolidação das pesquisas, objetos e procedimentos vinculados à História científica, bem como a consolidação das cátedras e do trabalho dos assistentes; e $2^{\mathrm{a}}$ geração (1971-1990), responsável pelo início dos primeiros cursos de pós-graduação no país, os quais voltaram-se também para novos olhares, temas, propostas metodológicas e extinção evolutiva das Cadeiras, além da constituição de produções acadêmicas mais regularmente organizadas e abertas para a ampliação do quadro de profissionais nas universidades. Naturalmente, a atuação da primeira geração de historiadoras pode se sobrepor à segunda, uma vez que elas também participaram da criação dos cursos de pós-graduação. Logo, a delimitação empregada na periodização das gerações será utilizada especialmente no sentido de facilitar a abordagem das mudanças inerentes ao conhecimento histórico produzido nas universidades, nas quais elas estiveram presentes.

Conforme a perspectiva atrelada às duas gerações, é necessário examinar de que forma as historiadoras e professoras das principais universidades públicas brasileiras teriam constituído sua trajetória intelectual, profissional e de vida. Não se trata apenas de examinar as trajetórias intelectuais notadamente de professoras com histórias paradigmáticas, modelares ou exemplares, mas também considerar aquelas que não tiveram grande visibilidade e reconhecimento. Valorizar-se-ão os aspectos diversificados relacionados às suas ações nos departamentos dos cursos de graduação e pós-graduação, congressos, conselhos editoriais de revista, âmbitos no quais os dilemas profissionais, dúvidas, tensões e decisões - quer sejam voltadas à vida profissional, quer sejam voltadas à vida pessoal e familiar - haveriam de se manifestar.

Ao elegermos a trajetória intelectual e biográfica das referidas professoras como objeto de análise, as questões condizentes às relações de gênero 
acabam sendo vistas como elemento de análise de grande importância para o estudo. Tais relações estão presentes no interior das disciplinas ou cátedras assumidas por elas no curso de História, nas relações com seus pares profissionais, na inserção delas na historiografia brasileira, nas pesquisas realizadas em universidades estrangeiras e na presença em outros âmbitos políticos e sociais. O reconhecimento de que a trajetória intelectual e de vida de cada professora foi circunscrita uma em relação às outras e todas em relação aos homens - ou seja, dos seus pares profissionais - sugere uma análise em que o gênero pode ser um componente mediador das diferenças entre as carreiras construídas por homens e mulheres.

A noção de gênero pretende se aliar também às reflexões sobre as diferenças masculinas e femininas no âmbito das origens socioculturais, origem familiar, escolhas relacionadas aos temas e procedimentos de pesquisa histórica e modos de inserção no sistema de cátedras, disciplinas assumidas, cargos de chefia, coordenação de conselhos editoriais e nas associações de professores. Nessa direção, supomos que no interior destas inserções que constituíram a trajetória intelectual e biográfica das historiadoras, as relações e representações de gênero nos permitem entender parte das assimetrias e dificuldades presentes em suas carreiras. Deste modo, é necessário investigar as situações diversas pelas quais passaram as referidas historiadoras para conseguirem se impor, divulgar seus trabalhos, valorizar-se mediante um local de trabalho marcadamente androcêntrico, consolidar e legitimar suas carreiras, fato que incide, portanto, no reconhecimento da existência de disputas simbólicas pela obtenção de projeção, liderança, prestígio e poder na instituição universitária.

Por fim, outros motivos que nos intrigam estão ligados à possibilidade de haver alguma tendência feminina nos objetos de pesquisa, nas obras dessas professoras e na própria prática de escrita, reflexões que poderiam indicar o "gênero da história". Contudo, esta problemática deve ser rigorosamente bem analisada e não se vincula e nenhum tipo de determinismo, pois observamos que carreiras e obras historiográficas do período delimitado estiveram também ancoradas, referidas ou ligadas a questões que envolvem o próprio ofício do historiador, como a neutralidade, imparcialidade, objetividade e análise correta das fontes, cujas características ajudaram a construir a ideia de que a história não tem gênero, nem classe, nem raça. Igualmente significativa, seria a abordagem espinhosa de se saber se as mulheres têm preocupações e interesses diferentes do que os homens quando escrevem sobre o passado. Se a criação de narrativas históricas é uma mera recita- 
ção dos fatos, sendo neutra e "verdadeira", então o sexo do autor não deve importar. Mas se Hayden White, Jörn Rüsen e outros que argumentam que a historiografia é "um produto construído pelo seu autor, o qual traz consigo uma experiência de vida que determina suas interpretações históricas" estiverem corretos, o sexo pode importar muito, desde que as mulheres possam escrever a História de maneira diferente dos homens.

Como saber se as mulheres, de maneira geral, são mais inclinadas a escrever sobre a História Social e não a História Econômica por uma vontade natural de suas subjetividades? Ou essa propensão ocorre porque as normas sociais em que são criadas e educadas as impulsionam nesse sentido? As historiadoras mulheres tendem ser mais críticas à violência e mais preocupadas com os detalhes biográficos dos sujeitos históricos? Por que a maioria dos historiadores das mulheres e de gênero tendem a ser mulheres? As respostas a essas perguntas geram controvérsias, mas para esse debate que tem suas raízes no campo epistemológico, é essencial que haja um questionamento assim.

\section{Referências}

BLAY, Eva \& Conceição Rosana R. da. A mulher como tema nas disciplinas da USP. Cadernos de Pesquisa, n 76, fev. p. 50-56, 1991.

BLAY, Eva; LANG, B. S. G. Mulheres na USP: Horizontes que se abrem. $1^{\text {a }}$. ed. São Paulo: Humanitas, 2004.

COSTA, Emília Viotti da. Entrevista com Emília Viotti da Costa. In: MORAES, José Geraldo Vinci \& REGO, José Márcio. Conversas com Historiadores Brasileiros. São Paulo: Ed. 34, 2002.

DAVIS, Natalie. "Gender and genre: women as historical writers, 1400-1820", Beyond Their Sex: Learned Women of the European Past. New York: New York University Press, 1980.

GOMES, Ângela de Castro. A República, a História e o IHGB. Belo Horizonte: Argvmentvm, 2009.

HONORATO, Cezar. Entrevista com Eulália Maria Lobo. Revista Rio de Janeiro, n. 10, maio-agosto. 2003.

PEROSA, Graziela S. A passagem pelo sistema de ensino em três gerações: classe e gênero na segmentação do sistema de ensino. Educação e Sociedade, Campinas, v. 31, n. 111, abr.-jun., 2010. 
PEROSA, Graziela S. Educação diferenciada e trajetórias profissionais femininas. Tempo Social: revista de sociologia da USP, v. 20, n. 1, 2005.

RUSEN, Jörn. Razão histórica: teoria da história: fundamentos da ciência histórica. Brasília: Editora Universidade de Brasília, 2010.

SMITH, Bonnie G. Gênero e História: homens, mulheres e a prática histórica. Bauru: EDUSC, 2003.

WOOLF, Virginia. Um teto todo seu. Rio de Janeiro: Nova Fronteira, 2005. 